Acta Poetica 26 (1-2)

PRIMAVERA-OTOÑO

2005

\title{
Elementos de oralidad en la literatura de cordel
}

\author{
Santiago Cortés Hernández
}

Este artículo analiza los elementos de oralidad que pueden encontrarse en la literatura de cordel atendiendo a dos líneas de estudio principales: la relación que existió entre los textos que se imprimieron en pliegos sueltos y las manifestaciones orales de la literatura, y las implicaciones textuales de esa relación. A partir del análisis de casos específicos, este estudio propone considerar la literatura de cordel como un medio de difusión con tendencia a reproducir materiales literarios relacionados de alguna forma con la cultura de la oralidad y presenta ejemplos de cómo esa relación incidía en la composición y difusión de los textos impresos en pliegos sueltos.

This paper analyzes the elements of orality which may be found in Hispanic chap-books considering them from two different views: the links they have oral culture, and the textual marks this links produced. Through the analysis of specific examples, the author considers Hispanic chap-books as a media that drifted toward publishing literary material related in some way to orality. 
Santiago Cortés Hernández

UNAM-Universidad de Alcalá

\section{Elementos de oralidad en la literatura de cordel}

\section{La literatura de cordel y los estudios sobre oralidad}

Desde hace algunos años se ha venido poniendo cada vez más en evidencia la importancia que tuvieron la oralidad y la voz para los textos hispánicos escritos e impresos durante el Renacimiento y el Barroco, e incluso para muchos textos de los siglos XVIII y XIX. El descubrimiento de ciertas formas de composición relacionadas íntimamente con la tradición oral y con la costumbre de la lectura en voz alta de los textos ha hecho necesaria la revisión de muchas ideas en torno a la invención, difusión y recepción de varios tipos de literatura de estas épocas, que a la luz de esas investigaciones adquieren otra dimensión. La literatura de cordel no es la excepción.

A medida que avanza nuestro conocimiento sobre los diferentes tipos de textos impresos en pliegos sueltos, se hace más claro que la literatura de cordel guarda una relación estrecha con un tipo de cultura en la que la oralidad juega un papel fundamental. El carácter popular de esta literatura, su materia textual, el papel del ciego como su difusor emblemático, su pervivencia durante un periodo de más de cuatro siglos, hacen necesaria la revisión de muchas de sus características a la luz 
de esa relación. A pesar de que muchos trabajos recientes sobre pliegos de cordel han incorporado de manera aislada observaciones más o menos detalladas sobre su relación con algunos elementos propios de la literatura oral, ninguno se ha dado hasta ahora a la tarea de hacer una delimitación clara del fenómeno ni de las líneas de estudio y problemas que se presentan al abordarlo.

El propósito de este artículo es plantear algunas ideas en torno a las relaciones entre la literatura de cordel y la oralidad desde dos perspectivas de estudio. La primera consiste en describir la relación que existió entre los textos que se imprimieron en pliegos sueltos y los tipos de oralidad que manejaba la cultura de la época. La segunda consiste en analizar las implicaciones textuales de esa relación, es decir, las marcas de oralidad que existen en la estructura, composición y disposición de los textos en los pliegos de cordel. Es necesario decir que no trataré aquí de un género literario específico dentro de la literatura de cordel, sino de los pliegos sueltos como un medio de difusión económico y práctico para difundir ciertos tipos de textos que se ajustaban a su formato y particularidades.

Para la primera línea de trabajo recurriré a las numerosas noticias que tenemos sobre las fuentes de la literatura de cordel y a la información disponible sobre la manera en la que ésta se difundía. A pesar de la variedad, complejidad y extensión temporal que estas noticias suponen, intentaré demostrar que hay elementos comunes que permiten establecer algunas constantes de importancia durante todo el periodo de publicación de pliegos sueltos. Se trata, pues, de describir la relación entre la literatura de cordel y la literatura oral, pero también de analizar la difusión oralizada de los pliegos sueltos y sus consecuencias dentro de un ciclo de transmisión que utiliza tanto la voz como el manuscrito o el impreso.

Dentro de la segunda línea de trabajo analizaré algunos de los rasgos más característicos y constantes de la literatura 
de cordel a lo largo de todo el periodo de su existencia, con la intención de mostrar algunas marcas que pueden observarse en los pliegos sueltos como resultado de la interacción con creadores, difusores y receptores para los cuales la oralidad era un factor de gran importancia; elementos como los grabados, los títulos y las fórmulas textuales, que constituyen un campo de estudio por sí mismos y que trazan una serie de relaciones que todavía requieren de mucha investigación.

\section{Elementos de oralidad en la producción y difusión de los pliegos de cordel}

Resulta curioso notar, para empezar este estudio, que el interés inicial por los pliegos de cordel derivó precisamente de su condición como vehículo para la primera impresión de varios tipos de literatura de tradición oral o de naturaleza oralizable, como el romancero o el teatro. Así, por ejemplo, no es para nadie desconocido que desde comienzos del siglo XVI "el romancero, renuente al manuscrito de escasa difusión, acepta ahora la real apropiación que hace de él la imprenta a través, sobre todo, de los pliegos sueltos" (García de Enterría 1988, 90) y que son estos una de las fuentes principales para el estudio del romancero viejo. También María Cruz García de Enterría afirma acertadamente que desde épocas muy tempranas

El teatro aparece también en esta forma de transmisión popular que es el pliego suelto o el libro de cordel. Pero las obras teatrales que encontramos impresas en esta época [siglo XVI] son más bien obras no marginadas por los contemporáneos ni - mucho menos - por los estudiosos posteriores, puesto que se ha trabajado sobre ellas para investigar los orígenes del teatro del Siglo de Oro. (García de Enterría 1983, 36)

De la misma manera, los trabajos que se han ocupado del estudio de la lírica tradicional, el cancionero o las oraciones 
de tradición oral en la Edad Media y el Renacimiento se han valido de los pliegos de cordel como fuentes para el rescate documental. Hay, pues, entre la diversa materia impresa de los pliegos sueltos y la oralidad literaria, una clara relación que se puede establecer desde los orígenes de los primeros y que será una constante a lo largo de toda su existencia, como lo prueba el hecho de la publicación ininterrumpida de todos estos materiales en pliegos de cordel hasta su desaparición en España en los albores del siglo xx.

Los investigadores que se han ocupado de alguno de los géneros impresos en pliegos de cordel se han percatado siempre de esa relación. Alan Deyermond, por ejemplo, al hablar de los pliegos sueltos que reprodujeron romances viejos durante el Renacimiento opina que en ellos "los elementos orales aparecen como tan fundamentales que no queda más remedio que pensar, al menos, en textos de carácter transicional" (Deyermond 1988, 41-42). Joaquín Marco, por su parte, nos dice que, durante el siglo XVIII, varias características confirman al "romance de pliego de cordel como literatura que se halla a mitad de camino entre la forma escrita y la oral" (Marco 1977, 70).

¿Pero en qué consiste exactamente ese "estar a mitad de camino" o ese estado de "textos de carácter transicional"? ¿Se refiere a la relación entre los pliegos y sus posibles fuentes orales o a las maneras de divulgación de estos textos impresos mediante su oralización? Me parece que en esa ambigüedad se define el tema de análisis de este estudio. En gran medida esa ambigüedad deriva del hecho de que la mayoría de los estudios sobre el material de los pliegos se han realizado siempre sobre un género o subgénero en particular. El considerar al pliego suelto como un medio de difusión que imprime material literario muy diverso me permitirá plantear aquí algunas ideas para delimitar las relaciones entre literatura de cordel y oralidad.

Al asomarnos al reciente Panorama de la literatura de cordel española de Francisco Mendoza Díaz-Maroto (2000) nos 
encontramos con un apartado en el que se clasifican dentro de los pliegos sueltos poéticos ciertos "pliegos relacionados con la tradición oral" (Marco 2000, 89), en los que el autor incluye aquellos que imprimen versiones de romances que primero se han creado, recreado y actualizado oralmente, y que después se han impreso ya como versiones bastante diferentes entre sí. Tal es el caso de los muchos pliegos con alguna versión del romance o "canción" de Gerineldo, o del Romance del Marqués de Mantua. Este criterio es perfectamente válido para plantear una visión panorámica de la literatura de cordel. ${ }^{1}$ Sin embargo, no es sólo a ese subgrupo de variantes producidas en la tradición oral y posteriormente impresas en pliegos al que me refiero aquí al tratar de la relación entre literatura de cordel y oralidad. Quiero considerar aquí una visión mucho más amplia de la literatura de cordel basada en la observación de que el pliego suelto siempre ha sido propenso a imprimir materiales relacionados de una $\mathrm{u}$ otra forma con una cultura de la oralidad y de que es ésta una de sus principales características, hasta ahora poco considerada. Si recorremos este $\mathrm{Pa}$ norama de la literatura de cordel española al que me he referido o cualquier otra visión panorámica sobre ella, podemos observar esa tendencia. Además de aquellos que imprimen material que proviene indudablemente de la tradición oral, encontramos pliegos cuya materia son las oraciones, las relaciones de sucesos, las historias heroicas de bandidos o de santos, los sermones, las historias caballerescas de distintos ciclos y, por supuesto, el teatro en forma de "sueltas", de piezas breves, de relaciones de comedias, etc. Tipos de literatura en mayor o menor medida popular, pero siempre en relación directa con alguna forma de oralidad: ya sea la de fuente directa - como en el caso de la poesía tradicional lírica y narrativa一, o la de ser textos planeados para la oralización y la representación

\footnotetext{
${ }^{1}$ Véase para la discusión de este tema, Mendoza Díaz-Maroto 1989, 53-57.
} 
- como el sermón o el teatro-, o bien la de su difusión oral mediante la lectura en voz alta o el canto - como las historias heroicas en prosa y las relaciones de sucesos-. A sustentar y explicar estas observaciones se dedicará el resto de este apartado. Comenzaré, para ello, por referirme a un caso específico.

Hasta hace unos años teníamos pocas certezas sobre la manera en la que se componía la literatura de cordel, sobre cómo llegaban a imprimirse en pliegos textos y temas de carácter tradicional, y sobre el papel del ciego y de la voz del pueblo como difusores o recreadores de esos textos. Poco a poco esos huecos en el conocimiento de la dinámica de la literatura de cordel se van subsanando. En el año 2002, Pedro M. Cátedra publicó bajo el título de Invención, difusión y recepción de la literatura popular impresa (siglo XVI), el estudio que ha aportado más datos concretos sobre esa dinámica. Se trata de un detallado trabajo documental sobre un pliego de cordel titulado Caso admirable y espantoso subzedido en la villa de Martín Muñoz de las Posadas, víspera de la Santísima Trinidad, en este año presente, que los demonios llevaron a un mal cristiano en hueso y en carne, el cual hera abogado en leyes, con otras cosas admirables y muchos avisos perteneçientes para qualquier christiano (Cátedra 2002, 377), y sobre su autor, Mateo de Brizuela, "ciego de poca vista" y "poeta que compone" (Cátedra 2002, 43), según sus colegas de oficio. La publicación de este pliego en 1567 ocasionó que se siguiera un proceso inquisitorial contra el autor de sus versos y contra su impresor, proceso que, rescatado por Pedro Cátedra, nos da información bastante detallada sobre la dinámica de composición y divulgación de un texto de literatura de cordel muy representativo dentro de los de su clase. Trataré de resumir esa información brevemente. ${ }^{2}$

\footnotetext{
${ }^{2}$ Remito al lector al excelente libro de Pedro Cátedra para los detalles del texto, del proceso inquisitorial y de la obra de Mateo de Brizuela, los cuales aparecen reproducidos y analizados ampliamente en el estudio y los apéndices.
} 
El proceso inquisitorial inicia con la querella impuesta por los herederos de un tal licenciado Gutiérrez, abogado en leyes y vecino de Martín Muñoz y Segovia, por la difamación que de ellos y del difunto abogado hace el pliego suelto que he citado arriba. Aunque los versos de Brizuela nunca mencionan el nombre de ese supuesto "mal cristiano" ni el de sus descendientes, era claro que quienes los escuchaban o leían, sabían perfectamente que se referían a ellos. Los testimonios que aparecen en el proceso inquisitorial nos van aclarando que en torno del licenciado Gutiérrez, muerto meses antes de la aparición del pliego, había crecido un rumor de pacto con el diablo, así como otro rumor que contaba que en su sepulcro se había enterrado un atado de paja porque el cuerpo del abogado había sido llevado por los demonios. Ese será el tema del Caso admirable y espantoso de Mateo de Brizuela, personaje itinerante en hábito de ciego de cuya ceguera caben varias dudas y autor de muchos otros textos publicados en pliegos de cordel. ${ }^{3}$ Vemos pues un caso en el que el texto de un pliego suelto recoge un pequeña historia oral que corre en la voz de una comunidad y la versifica para darla a la imprenta.

Pero hay más. Los testimonios del proceso nos informan que meses antes de la publicación del pliego el autor había recitado - oralmente, por supuesto - las "coplas" que hasta entonces había compuesto, a un colega suyo, ciego también, quien declara además que Brizuela componía "de memoria" y con la intención expresa de publicar sus versos en un pliego para venderlo. Tras la impresión, no sólo el pliego sino también su texto correrán como reguero de pólvora por un territorio que incluye al menos las ciudades de Valladolid, Segovia, Sevilla y los pueblos intermedios. Si separo aquí el pliego del texto es porque hay una buena cantidad de testimonios que

\footnotetext{
${ }^{3}$ De acuerdo con la hipótesis bastante convincente y fundamentada que presenta Pedro Cátedra, Mateo de Brizuela sería el autor de al menos seis pliegos diferentes dentro de los que se incluye, bajo el heterónimo de Mateo Sánchez de la Cruz, el de La renegada de Valladolid.
} 
dan fe de cómo las coplas se leían en público entre auditorios de los más diversos estratos sociales —desde artesanos de todos los oficios hasta letrados y curas que lo utilizaban como caso ejemplarizante- e incluso de cómo los versos se copiaron más de una vez en manuscritos que pasaron de mano en mano en un periodo de tiempo bastante corto.

Vemos, pues, el proceso completo de gestación de un texto típico de la literatura de cordel del XVI y de difusión de ese texto puesto en circulación por el soporte impreso del pliego de cordel. Ese proceso, como se puede ver, está inmerso en una cadena de manifestaciones orales: antes de su factura, inspirándola, se encuentran las historias que corren de boca en boca sobre un personaje; en su composición se encuentra el proceso de memorización y recitación del autor; y después de la publicación del pliego encontramos primero la voz del ciego que promociona mediante el canto y posteriormente la voz de la lectura colectiva que difunde el texto. Pero es necesario ir con cuidado en el análisis de esta dinámica, porque en medio de esa vorágine de oralidad, existe un elemento impreso que, sin duda, introduce una variante fundamental para el proceso y constituye el núcleo de nuestro estudio, por lo que es necesario observar sus funciones con detalle.

Es claro que el argumento que utiliza Brizuela para su historia se alimenta de un pequeño relato oral y que el autor se vale de técnicas de la literatura oral para la composición de sus versos: memorización, uso de fórmulas tradicionales, recitación de una parte de las coplas conforme las inventa, etc. También es claro que el texto impreso se encuentra inmerso, como pieza intermedia, en la cadena de difusión oral de una historia con tópicos y motivos populares: la historia que cuenta el pliego, a pesar de no mencionar el nombre del protagonista, es identificada claramente por sus escuchas con el rumor y el personaje que existían desde antes de la composición versificada. ¿Pero qué pasa con el texto y la historia cuando estos 
adquieren una forma fija al imprimirse en el pliego? Tratándose de la literatura de cordel en general, Pedro Cátedra opina que

La composición memorística del verso no implicaría en este caso una gran inestabilidad o fluidez textual. Quizá un tipo de poesía como la de cordel, narrativa y no lírica, cuya difusión dependía principalmente de profesionales, quienes, además, debían atenerse a un referente impreso que de hecho vendían, sea la excepción que confirme una regla que aún debe documentarse mejor. (Cátedra 2002, 61)

Hablando del Caso admirable y espantoso específicamente, en el que la difusión del texto corrió más a cargo de anónimos lectores colectivos que de ciegos "profesionales", también es su opinión que

no se produjo una reversión del texto poético original —sí, naturalmente, del hecho en forma de rumor-, sino que su destino es el de regularizarse o autorizarse por medio del escrito, en forma de traslado de mano. Reconoceremos, quizá, ahí una faceta más de la ambigüedad de la función del texto oral, escrito y "oralizado" en el Antiguo Régimen [...]. Pienso que la adquisición de la categoría de escrito de tan especiales características, al que se le reconoce autoridad por el hecho de estar impreso con licencia, requiere una autenticidad respaldada por lo escrito. (Cátedra 2002, 96)

Es cierto que los pliegos, impresos, daban a los textos un carácter fijo, una estabilidad superior a la de cualquier composición puramente oral, y una nota de autoridad heredada de la sacralización del texto que existió durante mucho tiempo. Esto lo prueba el hecho de que se hicieran copias manuscritas del pliego y de que algunos testigos afirmaran que el caso era verdadero porque había coplas impresas en las que se relataba. El proceso que Pedro Cátedra analiza de manera brillante 
nos da suficientes testimonios para comprobar ese carácter de autoridad del texto impreso.

Sin embargo, el hecho de que existiera un texto fijo en manuscrito o impreso no era equivalente en el caso de los pliegos sueltos a que éste tendiera a la regularización más allá de sus soportes escritos. Si bien es comprobable que algunos textos impresos y manuscritos presentaban poca variación, esto no indica que en su ejecución ante una audiencia o en su recreación oral posterior adquirieran también una forma fija. Esto es algo que sólo es demostrable mediante la observación de fenómenos de escritura y lectura paralelos a este caso. Durante la época en la que Brizuela compone su texto, tenemos bastante certeza de que tanto el impreso como el manuscrito se hacían no con el propósito de preservación que es característico de tiempos más recientes, sino con el propósito de ser leídos, de servir como cómplices de la memoria (Frenk 1997, 65 y ss.) y que por ese motivo "todavía en el siglo XVII un texto literario no se concebía, a la manera de hoy, como un objeto necesariamente fijo e incambiable, sino como una entidad que podía ser fluida, maleable, capaz de transformarse en sucesivas repeticiones" (Frenk 1997, 70). Me parece que estas afirmaciones adquieren mucho sentido si las vemos en el contexto del Caso admirable y espantoso que venimos analizando y en el contexto del pliego suelto como el transmisor material y efímero de un texto vivo más allá de ese soporte frágil.

Tal vez convendría apartarnos un poco del fenómeno comprobable de la estabilidad del texto impreso en pliegos sueltos para entrar en un terreno un poco más especulativo que nos llevaría a considerar la literatura de cordel como un fenómeno más complejo en el que interactúan muchos elementos orales. Apoyar estas especulaciones en un caso ya documentado pueden ayudarnos a comprender la literatura de cordel de manera más cabal. Como ha notado John D. Niles, "it is the interplay of both oral and literate systems of expression than must be 
taken into account if one hopes to account for the complexity of literature" (Niles 1999, 21). La pregunta que debemos plantearnos en este caso sería la siguiente: ¿cuál es exactamente la función de un pliego suelto como el del Caso admirable y espantoso dentro de la cadena de oralidad de la que forma parte y cuál es su relación con los elementos orales que lo rodean?

Para responder a esta pregunta debemos considerar a los pliegos sueltos dentro de un contexto en el que la palabra y la poesía, como manifestaciones orales, forman parte de un fenómeno de transacción social. El ciego o el poeta popular que compone versos es en este caso un donador de palabras para la comunidad. A cambio de lo que dona, el ciego espera recibir una remuneración económica, la cual será mayor cuanto mejor sea la interacción entre el compositor-difusor y su audiencia. Brizuela y sus colegas de oficio que utilizaban técnicas y medios orales para componer y difundir sus textos, debieron componer versos que fueran funcionales dentro de esta dinámica, es decir, textos que estuvieran pensados para difundirse oralmente con éxito ante una audiencia, porque aunque existiera el pliego impreso, era la oralización del texto su forma de difusión y lectura. Como estos compositores populares vivían en una era en la que la imprenta era también un medio accesible, tenían al alcance un factor más para potenciar y autorizar la difusión de un texto planeado para la oralización: el pliego suelto. La impresión en pliegos de un texto de este tipo no debe hacernos perder de vista la naturaleza oral subyacente en su composición y difusión. Debemos considerar que aunque un texto de composición oral se ponga por escrito, su oralidad permanece latente y lista para ser reactivada por la voz de los recreadores competentes. ${ }^{4}$

Cuando las coplas de uno de estos poetas populares estaban completas, entonces eran llevadas a la imprenta. En ese mo-

\footnotetext{
${ }^{4}$ Véase lo que dice John D. Niles $(1999,19)$ al respecto, utilizando el término strong tradition-bearer.
} 
mento se da un fenómeno paralelo al que sucede cuando cualquier composición oral se registra por escrito o por cualquier otro medio, y que conviene delinear aquí brevemente. Sea cual sea la manera en la que el poeta popular hiciera llegar sus palabras a la imprenta, escribiéndolas él mismo o dictándolas a alguien más, en ese proceso se da una situación particular: es una producción de un discurso planeado para su oralización, pero en ausencia del auditorio y con el propósito de producir un texto escrito. Muy probablemente el ciego o cualquier otro poeta popular no recordara en ese momento el texto de la misma manera que lo hacía ante un auditorio, por lo que tal vez sea necesario considerar a los pliegos sueltos, dentro de un contexto a la vez de oralidad y de soportes impresos, "as a tertium quid: a third type of creation, a unique hybrid that comes into being at the interface of orality and literacy througth an unknown person's prompting and a subsequent process of text-making" (Niles 1999, 104).

Después de que esa composición se imprime en pliegos sueltos, también hay una serie de elementos de oralidad a considerar en cuanto a su difusión. Si bien la relativa estabilidad que implica la composición memorística de un texto narrativo y la definitiva fijeza que éste adquiere al imprimirse deben ser tomados en cuenta al hablar de éste y otros muchos casos de literatura de cordel, también hay que tomar en cuenta que aquel que vende el pliego — más aún si es él mismo quien ha compuesto el texto y es capaz de modificarlo a voluntad-a pesar de tener ese referente impreso, no tiene motivos para atenerse a él rigurosamente. Más bien al contrario. Juega aquí un papel fundamental la figura del ciego como difusor emblemático, aunque no exclusivo, de la literatura de cordel: el ciego, privado de la vista corporal y por lo tanto de la capacidad de leer mientras produce un discurso, difunde los textos porque es capaz de retenerlos en la memoria y recrearlos para su promoción. Cualquier otro recreador hábil de discursos tradi- 
cionales podría seguir también el mismo proceso de apoyo en el impreso y de producción y recreación oral del texto.

Pienso que a partir de un caso tan bien documentado y tan representativo de un tipo de literatura de cordel, podemos concebir a los pliegos sueltos como un eslabón atípico dentro de una cadena de manifestaciones orales. El hecho de que los pliegos sueltos sean el único elemento conservado de un complejo fenómeno de creación y recreación en el que la cultura de la oralidad jugó un papel fundamental, es, en mi opinión, lo que ha ocasionado que se pierda esta perspectiva del fenómeno completo de creación de estos textos. ${ }^{5}$ En el caso del texto de Mateo de Brizuela, por ejemplo, podemos observar cómo un hecho concreto de la realidad motiva la creación de una pequeña narración oral; cómo esa historia tiene múltiples manifestaciones individuales, una de las cuales son los versos compuestos por ese "profesional de la recreación" que es el ciego hacedor de coplas; cómo ese texto llega a la imprenta y su contenido, por ese motivo, se difunde tanto de manera oral como oralizada, impresa y manuscrita; y, finalmente, cómo la historia y sus diversas manifestaciones, incluido el pliego impreso y los manuscritos cómplices de la memoria, siguen su camino de recreación. Más aún, debemos considerar este fenómeno dentro de un proceso mucho más amplio de oralidad en el que la recreación de tópicos y motivos va produciendo, algunas veces en la voz y otras apoyándose en el soporte del papel, textos artísticos de las

\footnotetext{
${ }^{5}$ Es, por ejemplo, el caso del gran bibliógrafo Antonio Rodríguez Moñino, en cuya opinión "conoce el pueblo la poesía desde el siglo XVI a nuestra época, casi con exclusividad a través de los cuadernillos distribuidos sobre el territorio peninsular por los vendedores ambulantes, principalmente ciegos, que los llevan a los más apartados rincones. La crítica ha desconocido un principio que, a mi modo de ver, es fundamental y es que sin esta permanente difusión sería imposible encontrar apoyo a la transmisión oral, no exclusiva en la tradicionalización del romancero, por ejemplo. El pliego ha actuado como rodrigón de lo transmitido oralmente y sin él no se puede contemplar aquélla sino como un milagro" (Rodríguez Moñino 1968, 51). Opinión con la que, por supuesto, estoy en desacuerdo y de la que otros autores como Mendoza Díaz-Maroto $(2000,89)$ ya han diferido.
} 
más diversas calidades. ${ }^{6}$ Conviene recordar aquí las palabras en las que Margit Frenk nos recuerda que "no tenemos acceso ni a la voz, ni a la memoria de los hombres de aquel tiempo; tampoco podemos compartir con ellos su manera de vivir los poemas. Pero tenemos los manuscritos [y los impresos, agrego], y si sabemos leerlos veremos cómo de una manera secreta albergaban memoria y voz, y un entusiasmo infinito por la poesía" (Frenk 1997, 72).

Podemos responder ahora en qué consiste exactamente esa naturaleza que hace al texto del pliego suelto "estar a medio camino entre lo escrito y lo oral" y lo que le da su "carácter transicional": los pliegos sueltos "constituían una verdadera 'superficie de contacto' entre lo oral y lo escrito en los tiempos modernos" (Cátedra 2002, 61) porque su naturaleza de impresos los constituía como un eslabón escrito y fijo dentro de un fenómeno de creación y difusión donde el resto de las piezas no lo eran. Su función dentro de ese fenómeno, al menos en el caso que venimos analizando, es la de crear la apariencia de autoridad y de verdad mediante el prestigio de la escritura y el impreso, pero no por ello su texto se vuelve estable en la ejecución, ni dejan los pliegos de estar llenos de elementos de carácter oral, ni de obedecer a muchas de las técnicas de creación de la oralidad, ni de estar vinculados a los medios y leyes de la difusión oral, potenciada y modificada hasta cierto punto por la imprenta. ${ }^{7}$

\footnotetext{
${ }^{6}$ El motivo del pacto con el diablo para obtener bienes materiales o sabiduría, así como el del alma llevada por el demonio son identificables en numerosos cuentos, exempla, pliegos sueltos y otras obras hispánicas, como por ejemplo las comedias El esclavo del demonio de Mira de Amescua o El mágico prodigioso de Calderón de la Barca. Julio Camarena y Maxime Chevalier presentan en su Catálogo tipológico del cuento folklórico español: cuentos maravillosos un cuento que presenta varios puntos de contacto con este tema bajo el tipo 361 [el esclavo del demonio]. Véanse para su identificación con el folclor universal los motivos E752.2 (Soul carried of by devil) y G303.25.28 (Devil follows corps when a lawyer is burried) en el catálogo de Stith Thompson. Podemos identificar, además todas estas obras con el tipo cuentístico de El mago y su alumno clasificado con el número 325 en el catálogo de Aarne y Thompson. Véanse además las referencias que da José Manuel Pedrosa 2004, 161-164.

${ }^{7}$ Véase el tercer apartado del artículo de James Foley "South Slavic Oral Epic
} 
Hechas estas afirmaciones un tanto aventuradas, es necesario dejar ahora el terreno firme del Caso admirable y espantoso compuesto por Mateo de Brizuela para entrar en el territorio diverso de la literatura de cordel y observar cómo cada tipo de pliego, dependiendo de su material, cumple en mayor o menor medida con las condiciones descritas.

Ya he anotado arriba que hay una tendencia en la inmensa mayoría de pliegos sueltos a reproducir material relacionado de una u otra forma con la oralidad. Me parece que el análisis del caso de Mateo de Brizuela sugiere que hay una buena cantidad de pliegos que cumplen esa condición de la misma manera, es decir, que son medios impresos en los que se difunden textos compuestos para la oralización, que se alimentan de la tradición oral y que conforman un eslabón atípico en la cadena de la transmisión principalmente oral de un texto. En el caso de los numerosos pliegos que reproducen poesía de tradición oral -romances viejos, cancioncillas, etc.- un texto modelado por la colectividad es tomado directamente de esa tradición o de otro pliego que lo ha reproducido antes tomándolo de ella. En pliegos como el del Caso admirable y espantoso el texto reproducido no es tradicional en el sentido pidaliano del término, pero, como hemos visto, ese texto de un autor individual -que utiliza muchas de las técnicas tradicionales para componer - se encuentra inmerso en la cadena de la transmisión oral, se alimenta de los productos de una oralidad colectiva y se integra a la difusión de los mismos aunque de una nueva manera condicionada por su carácter impreso. En ese mismo caso se encuentran un sinfín de pliegos que imprimen relaciones de sucesos e historias de casos prodigiosos, de maravillas y de monstruos. Pero también en buena medida es el caso de muchos de los pliegos sobre contrabandistas y bandidos, tan abundantes sobre todo durante el siglo XVIII, los cuales traba-

and the Homeric Question”, publicado en este mismo volumen, para más información sobre las diversas relaciones entre el impreso y el texto oral. 
jan sobre la figura del trickster o del bandido generoso y cuyas historias suelen ser una acumulación de leyendas en torno a esas figuras más o menos mitificadas.

El texto impreso en pliegos de cordel, debido a su forma de difusión tanto escrita como oralizada, inmersa en un mundo de oralidad, suele adquirir variantes de importancia si se vuelve a imprimir. En el caso de los pliegos que reproducen textos tomados directamente de la tradición oral, esas variantes suelen ser muy distintas entre sí. Tal es el caso, por ejemplo, de las múltiples versiones del romance de Gerineldo impresas en pliegos de cordel. Éstas van desde una versión impresa en un pliego suelto de 1537 que, según Mercedes Díaz Roig, es una de las más antiguas "y la que está más cerca de las muchas versiones [...] de la tradición oral moderna" (Díaz Roig 2003, 291n), pasando por numerosas versiones del siglo XVIII, hasta una de 1854, impresa en Madrid por José Marés, que lleva el curioso y revelador título de Canción nueva titulada Gerineldo, en la que se espresan los amores y fuga de un oficial ruso con la bella Enildas, sultana favorita del gran Señor. ${ }^{8} \mathrm{La}$ publicación en pliego suelto de un texto de tradición oral no supone, pues, una estabilidad para el mismo, pero sí altera su forma de difusión y produce fenómenos distintos dentro de la cadena de la transmisión, como se puede ver en algunos ámbitos en los que los pliegos sueltos han sido de importancia fundamental para la conservación y difusión de romances, como en el caso de La Gomera (Salazar 2003, 219ss. y Mendoza Díaz-Maroto 1989, 295ss.). Los pliegos que imprimen textos como el del Caso admirable y espantoso, por su parte, no presentan variaciones tan grandes, pero sus versos siempre están sujetos a cierta inestabilidad que, como se verá en el siguiente apartado, no se debe sólo al descuido de los impresores, sino también a ese concepto del texto maleable y a su paso por la

\footnotetext{
${ }^{8}$ Francisco Mendoza Díaz-Maroto (2000, 92-93) reproduce la portada de este pliego y otro con la "canción nueva" de Gerineldo.
} 
voz popular en su proceso de difusión. Tal vez convendría hablar, entonces, de una inestabilidad propia del texto impreso en algunos pliegos de cordel, que en mayor o menor medida y a semejanza de los manuscritos de cancioneros dedicados a la oralización, "no constituían sino hitos dispersos en el circuito de la difusión, el cual solía ir del texto a los ojos de un lector, de los ojos a la voz y al oído, o a la memoria, a la voz, al oído... y que solía desembocar nuevamente en un texto escrito" (Frenk 1997, 58).

Hay un tipo de pliegos sueltos a los que el material proveniente de la tradición oral les llega diferido por otras fuentes, pero aun así su carácter y su relación con la oralidad no son tan diferentes de los que venimos analizando. Me refiero a los numerosos pliegos hagiográficos. A pesar de que en ellos el valor de la palabra escrita e impresa tiene un peso evidente de autoridad, los pliegos hagiográficos también están íntimamente relacionados con fuentes y maneras de difusión orales. Por un lado, porque en ellos hay, diferida, una tradición oral en la composición de las historias: recordemos que la tradición hagiográfica recopila originalmente una serie de leyendas orales que construyen su historia en torno a una figura específica de héroe y una serie de motivos folclóricos. Por otra parte, las historias de santos que se imprimen en pliegos sueltos se diferencian muchas veces de aquellas que encontramos en los tratados hagiográficos como los Flos Sanctorum de Pedro Ribadeneyra o de Alonso de Villegas; los pliegos sobre vidas de santos no están interesados en la "veracidad" ni en el dato histórico del tratado, sino en la maravilla que es capaz de convertirse en una historia popular para entrar al circuito de la difusión de la misma manera que los pliegos que hemos visto anteriormente, por medio de la voz. Como ha dicho ya Julio Caro Baroja, en estos pliegos "los temas se ajustan a la capacidad de un público ávido de relatos tremendos o tremendistas, persuadido de que los dramas de la vida son los que le dan 
a esta más significado, sean protagonistas de ellos los santos o los pecadores: y si son santos que antes fueron pecadores, mejor que mejor" (Caro Baroja 1990, 163). ${ }^{9}$

Tanto en el caso de las hagiografías impresas en pliegos sueltos como en el caso de toda la literatura de cordel de la que nos hemos ocupado hasta ahora, el estudio y la documentación futura de casos individuales podrá ir comprobando o desmintiendo, o puntualizando lo que he propuesto en estas líneas. Me parece, sin embargo, que la tendencia general que muestran los pliegos de cordel a imprimir material relacionado con las expresiones literarias orales se puede ver hasta ahora bastante clara. Para terminar con este apartado y seguir aclarando esa relación, quiero referirme a un tipo de pliegos bastante numerosos que imprimen material literario que ha sido escrito expresamente para su oralización: el teatro.

Durante todo el periodo de su existencia, la literatura de cordel siempre incluyó textos teatrales como uno de sus materiales más exitosos. Para nadie es desconocido que "una gran parte de nuestro primitivo teatro se imprimió en pliegos sueltos mínimos, góticos" (García de Enterría 1973, 27) y que una gran parte del teatro español del Siglo de Oro se publicó por primera vez también en ediciones "sueltas", que no eran sino folletos de entre 16 y 40 páginas (Mendoza Díaz-Maroto 2000, 186-187). Además encontramos publicados con profusión en pliegos sueltos monólogos, loas, entremeses, diálogos, sainetes, pasillos y, sobre todo, relaciones de comedias. La abundancia de textos teatrales publicados en pliegos de cordel ha sido explicada de varias formas por más de un autor. Julio Caro Baroja, por ejemplo, ha llamado la atención sobre la abundancia "de los romances que se hicieron ex profeso para ser re-

\footnotetext{
${ }^{9}$ La trayectoria de transmisión que seguían las historias de santidad que aparecían en pliegos sueltos, sin embargo, puede presentar caminos bastante azarosos. Véase, para un caso en el que una de estas figuras de santidad del cordel del siglo XVIII deriva de una comedia de Felipe Godínez (Cortés Hernández, 2003).
} 
presentados en tertulias" y ha visto en el gusto de mozos y mozas aficionados a la recitación una justificación para la existencia de las relaciones de comedias (Caro Baroja 1990, 211 y 219). Otros autores, como Francisco Mendoza Díaz-Maroto, han observado también que el vehículo del folleto y del pliego "habitualmente servía para hacer llegar de algún modo el teatro a los habitantes de lugares que carecían de corral de comedias, o para emular a los actores profesionales" (Mendoza Díaz-Maroto 2000, 183). Ambas afirmaciones son definitivamente ciertas, pero también es cierto que la abundancia de material teatral en los pliegos de cordel viene a confirmar esa propensión de la literatura de cordel a reproducir material relacionado con la oralidad, que en este caso es material fácilmente oralizable debido a que ha sido escrito con ese propósito expreso. Este hecho, por simple que parezca, podría arrojar mucha luz sobre algunos puntos obscuros de la historia de la literatura de cordel y de la compleja historia de la literatura popular.

Siempre ha intrigado a los interesados en esta materia, por ejemplo, el hecho de que durante el barroco, durante el siglo XVIII e incluso durante una buena parte del siglo XIX, se publicaran abundantemente relaciones de comedias escritas durante el Siglo de Oro, es decir, que en los pliegos de cordel siguieran apareciendo durante tanto tiempo "aquellos parlamentos puestos en boca de un solo personaje, de carácter casi siempre narrativo y en los que se nos explica, con un lenguaje - nótese esto- recargado y barroco, alguno de los elementos clave de la acción dramática" (García de Enterría 1983, 39). Algunas veces la permanencia de las relaciones de comedia dentro de la literatura de cordel se ha explicado como una compensación por las prohibiciones que hubo para representar teatro durante algunos años en ciertos lugares de España. ${ }^{10}$ Aunque esa relación es

${ }^{10}$ Estas explicaciones pueden encontrarse, por ejemplo, en el trabajo de Manuel Alvar (1970, 348ss) sobre un tomo facticio malagueño de pliegos sueltos, o en el artículo de Jaime Moll (1976). 
perfectamente probable y puede haber incidido en la cantidad de relaciones publicadas, esto no nos explica el gusto popular por esos versos provenientes del teatro y de un barroquismo recargado que se mantuvo mucho más allá de los años de prohibición.

Es necesario plantearse aquí una pregunta muy similar a la que pusiera a Margit Frenk, hace ya algunos años, en el inicio de una investigación sobre la importancia de la oralidad en los textos del Siglo de Oro. ${ }^{11}$ ¿Cómo es posible que el público de los pliegos de cordel, tan menospreciado por muchos, entendiera y fuera afecto durante tanto tiempo a textos tan complejos y sofisticados, abundantes en figuras retóricas y por añadidura escritos en verso y aislados de su contexto original de representación y de la obra original? La respuesta bien puede encontrarse en algunas de las propuestas que he venido desarrollando. Ese público debió de estar en contacto con obras literarias de diversos tipos mediante la voz y, sobre todo, acostumbrado a entenderlos mediante su oralización, que era la manera natural de difusión de estos textos porque habían sido escritos para ser entendidos de esa forma. Así, la relación de comedia se conservaría entendible y en el gusto del público de la literatura de cordel debido a su naturaleza de texto planeado para la oralización. Pero también se puede explicar esta permanencia de las relaciones de comedia en los pliegos sueltos porque aquellos parlamentos donde se resumía la acción de la comedia ofrecían a los impresores un tipo de material que los pliegos siempre habían reproducido, es decir, un texto escrito generalmente en romance que contaba en pocos versos - de la manera excepcional en que los autores dramáticos del barroco sabían hacerlo y que los autores de pliego poco a poco iban perdiendo - el argumento de una historia de forma tal que era perfecta para su oralización.

\footnotetext{
11 Véase Frenk 1997, 5.
} 
El estudio que analice el comportamiento de la publicación de material teatral en pliegos de cordel está aún por hacerse. Ese estudio nos permitirá entender muchas otras cosas sobre la dinámica que venimos analizando, como por ejemplo, cuáles piezas teatrales se preferían, cómo se seleccionaban los versos que conformarían la relación de comedia, cómo llegaban los textos de la comedia al pliego, etc. Por ahora podemos decir, por algunos testimonios, que aquello que se escuchaba en las comedias $-\mathrm{y}$ tal vez también en sus "relaciones" de pliego- estaba sujeto a los mismos procesos de memorización general y difusión por medio de la voz, y que los textos teatrales impresos en pliegos sueltos, completos, fragmentados o resumidos, mostraban la misma inestabilidad que es característica de la literatura de cordel e incluso podían correr manuscritos. En la Dorotea, por ejemplo, Julio dice a Don Fernando: "Quiero dezirte unos versos que oí en una comedia, a propósito de tus celos" (III, 1). Y Lope de Vega, en ese Memorial sobre el que ha corrido tanta tinta desde su descubrimiento, afirma también que "es justo que V[uestra] Alt[eza] advierta en remediar que los libreros no vendan papeles manuscritos con retulos de comedias", y reclama que los escritos que se vendan sean aquellos que salen del autor, "vistos y corregidos por su mano, y no después de aver passado por tantas, que si la tercera no es del autor, ¿qué será después de infinitas?"12

Muchas cosas quedan por estudiar aún con respecto a esta relación entre el pliego suelto como medio de difusión y la cultura de oralidad. Por ejemplo, las numerosas oraciones que aparecieron como literatura de cordel y en las que la oralización jugaba un papel evidente, o las abundantes "aleluyas" que constituían una verdadera "poesía para los ojos" (Mendoza DíazMaroto 2000, 55) y que adaptaban obras literarias a un sistema de grabado y "mote" para imprimirse en hojas volantes.

\footnotetext{
12 Tomo la cita de la reproducción facsimilar del Memorial de Lope de Vega (García de Enterría 1973, 88-89).
} 
O bien, la manera en la que se oralizaban y difundían los pliegos que contenían obras en prosa provenientes de fuentes escritas. También falta por estudiar detalladamente cómo esta relación se fue modificando a lo largo de los siglos en los que se publicó literatura de cordel y en los que fue cambiando la manera de leer y difundir los textos, estudio que muy probablemente presentará numerosas excepciones a lo que he propuesto en estas líneas porque el fenómeno es mucho más complejo de lo que cabe aquí analizar. Pero ahora es necesario referirse a algunas implicaciones textuales de la relación entre literatura de cordel y oralidad para terminar las propuestas de este artículo.

\section{Marcas textuales de oralidad y oralización en los pliegos sueltos}

El fenómeno de intensa relación entre formas de la oralidad y literatura de cordel que he descrito a grandes rasgos no podía sino dejar múltiples marcas en los textos impresos en pliegos sueltos. Éstas ya han sido notadas de manera aislada por varios autores en estudios anteriores, pero conviene revisarlas a la luz de las propuestas que he hecho. Ante la imposibilidad de hacer aquí un análisis exhaustivo de todas estas marcas me limitaré a examinar las que podemos encontrar en tres elementos que son característicos de toda la literatura de cordel: el título, el grabado y algunas fórmulas que encontramos en los inicios y finales de los textos.

El título de los pliegos de cordel tiene una función claramente publicitaria que ya ha sido advertida por muchos investigadores. María Cruz García de Enterría, por ejemplo, ha notado que el título es una parte funcional importante dentro de la estructura de los pliegos, la cual apelaba al 
deseo de novedad y la nostalgia o, incluso, la necesidad de la tradición. [...] La función publicitaria del título en el pliego de cordel queda perfectamente clara [...] y entendemos aquí la publicidad no sólo como actividad del autor o del impresor dirigida hacia una venta mayor del pliego, sino también como utilización de unos sintagmas cuyo contenido semántico orientaba o debía orientar no sólo a la compra sino a la lectura del romance. (García de Enterría 1983, 54-55)

Dentro de esa función publicitaria y atendiendo a la orientación de la lectura que propiciaban, los títulos del pliego de cordel tienen también una serie de elementos relacionados con algunas técnicas de la narración oral. Tanto por testimonios de algunas obras como por estudios sobre pliegos sueltos, podemos suponer que los títulos y los demás datos preliminares, como los poemas que rellenaban los espacios sobrantes del pliego, la aprobación y la licencia, solían pregonarse también dentro del "ritual" de recitación del ciego. ${ }^{13}$ Éstos funcionaban, pues, como una especie de anuncio mediante el cual debía captarse la atención de un público que, como hemos visto, estaba acostumbrado a escuchar los textos oralizados pero participaba también de la transmisión de una serie de textos tradicionales y tradicionalizados. Es lógico que esa llamada de atención emulara varios de los métodos usados por la transmisión oral.

El hecho de que el título del pliego suelto apele tanto a la novedad como a la tradición es sintomático porque esto coincide claramente con dos elementos que Walter Ong ha señala-

\footnotetext{
${ }^{13}$ En el tranco VI de El Diablo Cojuelo, Vélez de Guevara narra cómo: “estaban unos ciegos sobre un banco, de pies, y mucha gente de capa parda de auditorio, cantando la relación muy verdadera que trataba de cómo una maldita dueña se había hecho preñada del diablo, y que por permisión de Dios había parido una manada de lechones, con un romance de don Álvaro de Luna y una letrilla contra los demonios que decía: Lucifer tiene muermo / Satanás, sarna..." (Vélez de Guevara 1988, 160-161). Sin embargo, no sabemos si esos ciegos se valían de un pliego y si ese romance y esa letrilla se pregonaban al inicio o en la parte final. Véase para otras referencias el estudio ya citado de Pedro Cátedra (2002, 81-82 y 225-230), y el libro de Jean-François Botrel (1993, 124 y 134-137).
} 
do como característicos de las narraciones orales. En ellas, "los elementos, temas y fórmulas, y su uso corresponden a una tradición claramente identificable. La originalidad no consiste en la introducción de elementos nuevos, sino en la adaptación eficaz de los materiales [...] a cada situación o público único e individual" (Ong 1996, 64-65). Así es como en los pliegos sueltos encontraremos con una frecuencia contundente encabezados que comienzan con "Nuevo romance" o "Canción Nueva" sin importar que se trate de una relación de sucesos de invención reciente o del más antiguo romance tradicional. Ese tipo de combinaciones tan comunes en pliegos poéticos sintetizan en dos palabras su relación con las técnicas de la oralidad narrativa: por un lado la apelación a la novedad del texto que se va a escuchar y por otro el apego a una tradición en este caso representada por la forma del romance o la canción.

Pero aunque los pliegos no presenten explícitamente este tipo de sintagmas en sus encabezados, sus títulos apelarán de alguna u otra forma a la tradición y a la novedad. Muchas veces la novedad estará pregonada por lo llamativo del caso que se relata y la tradición consistirá en ofrecer, sintetizados dentro del título, los motivos clave de la narración que son reconocibles - consciente o inconscientemente, por formar parte de una tradición a la que pertenecen - para los lectores o escuchas. Es lo que pasa, por ejemplo, con el título del Caso admirable y espantoso [...], que los demonios llevaron a un mal cristiano en hueso y en carne, el cual hera abogado en leyes. Mientras que la primera parte apela a la novedad, la segunda apela a dos motivos folclóricos muy conocidos dentro de la cultura hispánica. Un hermoso ejemplo de este fenómeno nos lo da un pliego suelto prosístico del siglo XIX, publicado en Madrid, por los sucesores de Hernando, y que lleva por título Historia del esforzado Clamades y la hermosa Clarmonda, o sea, El caballo de madera. En la parte final de este título podemos advertir claramente la necesidad de vincular la historia a la tradición ape- 
lando a su nombre más conocido. Fácilmente reconocible para el público, la historia del caballo mágico de madera que el caballero utiliza para buscar a la dama se encuentra, en efecto, en la literatura, tradicional y culta, de todas las épocas: en Las mil y una noches, en varios textos medievales, en folletos portugueses, inspirando el episodio de Clavileño en la segunda parte del Quijote, etcétera. ${ }^{14}$

Por otra parte, los títulos de la literatura de cordel suelen también apelar en varias formas a esa "adaptación eficaz de los materiales" o actualización. A menudo la actualización está dada al situar la historia en un contexto espacio-temporal específico y conocido. Es el caso, otra vez, del Caso admirable y espantoso subzedido en la villa de Martín Muñoz de las Posadas, víspera de la Santísima Trinidad, en este año presente, y de tantos otros pliegos sobre maravillas y sucesos notables. Pero también a veces la actualización consiste en la adaptación de los personajes a nuevos contextos históricos o referenciales, los cuales se reflejan en el título, como en el ya citado pliego de ese Gerineldo decimonónico en el que se espresan los amores y fuga de un oficial ruso con la bella Enildas, sultana favorita del gran Señor (vid. supra).

Muchos de los títulos de los pliegos de cordel suelen además contener un pequeño resumen de la narración, incluso de su desenlace. Por ejemplo: La espantosa y maravillosa vida de Roberto el Diablo, hijo del duque de Normandía, el cual después fue llamado hombre de Dios, pliego barcelonés de 1851. O bien: Romance del Marqués de Mantua, el qual trata como andando a cassa, halló a su sobrino Valdovinos con heridas de muerte, al qual hirió el príncipe don Carloto por casar con su esposa. Es muy doloroso y bien compuesto. Con la sentencia de don Carloto al fin, pliego valenciano del siglo XVIII. Esa enun-

14 Véase la reproducción de la portada de este pliego que incluye Mendoza Díaz-Maroto (2000, 200-201), ahí mismo véanse las interesantes referencias bibliográficas sobre la tradición de la que proviene su texto. 
ciación de la historia completa en los títulos de pliegos sueltos coincide también con una estructura muy clara de las narraciones orales, en la que el inicio presenta, justamente, un resumen de la trama. ${ }^{15}$ Esto podemos notarlo incluso en costumbres modernas de narración oral, como en el caso de leyendas o de chistes que comienzan por preguntar al interlocutor si conoce la historia que se contará a continuación. Hasta aquí los títulos.

Entre las muchas cosas que faltan por analizar sobre los grabados en los pliegos de cordel, quiero apuntar aquí solamente la manera en que éstos funcionaban junto con los títulos en el momento de la difusión del pliego suelto. Los grabados de la literatura de cordel, como es bien sabido, eran reutilizados de un pliego a otro y solían incluso proceder, como piezas sueltas, de grabados utilizados para algún libro. Esto está en clara relación con el carácter económico del pliego suelto: no podían encargarse grabados para la impresión de un pliego, sino que se utilizaba para esas "menudencias" el material del que se dispusiera. Pero tampoco se necesitaba más para este propósito. El grabado forma parte del aparato de publicidad del pliego, pero a sabiendas de que la carátula de éste se pregonaba igual que su texto en el momento de la oralización, nos damos cuenta de que el grabado funcionaba en ese "acontecimiento" como una ayuda del discurso oral. La imagen, por más inexacta que fuera, proporcionaba al auditorio una representación sensible de aquello que el ciego o cualquier otro lector contaba. Así, junto con los pies de imprenta que presentaban licencias y aprobaciones muchas veces falsas, los grabados del pliego no buscaban la expresión de grandes significados, sino servir como apoyo y como de marca de veracidad en el impreso de un discurso destinado a la oralización.

\footnotetext{
15 Recordemos que la cultura puramente oral "no puede organizar ni la narración más breve de la manera climática implacable y elaborada que los lectores de la literatura de los últimos 200 años han aprendido a desear cada vez más" (Ong 1996, 140) y que de ahí deriva la enunciación inicial del asunto y la estructura episódica de muchas narraciones orales.
} 
Quiero terminar este artículo refiriéndome, brevemente, debido a su carácter ya estudiado y muy conocido, a un tipo de marcas que aparecen en los textos de la literatura de cordel como resultado de su relación con la cultura de la oralidad y sobre todo, en este caso, de su condición de textos planeados para su lectura en voz alta. Me refiero a todas esas fórmulas que aparecen sobre todo en el inicio y en el final de relaciones de los más diversos tipos publicadas en pliegos sueltos. En el léxico de éstas podemos encontrar numerosas alusiones al carácter aural de los textos, mientras que en el carácter formulaico de esos inicios y finales podemos ver reflejadas claramente la mayoría de las propuestas que he venido desarrollando. El carácter oralizable de los textos sería aquí la causa de que aparecieran en estos impresos constantes interpelaciones a un auditorio que está en el "horizonte de expectativas" del texto. La relación con la transmisión oral y con el tipo de composición de estos textos sería, por su parte, una explicación para ese carácter formulaico evidente. $^{16}$

A medida que vayan avanzando las investigaciones sobre casos específicos dentro del vasto panorama de la literatura de cordel podremos ir desentrañando con más detalle el papel que ésta jugaba dentro de una cultura en la que la oralidad y la oralización de los textos eran factores de gran importancia para la literatura. También podremos entender más claramente la manera en la que ese papel se fue modificando en distintas épocas. He querido contribuir aquí, aunque sea de manera superficial, al estudio de cómo muchas de las características de los pliegos sueltos coinciden con algunas de las grandes leyes del estilo oral, de cómo la literatura de cordel era muy propensa a reproducir material relacionado con manifestaciones de la literatura oral, y de cómo esa relación nos ayuda a contextualizar más cabalmente la dinámica de los pliegos de cordel y sus textos.

\footnotetext{
16 Véase, entre otros, los abundantes ejemplos de este léxico y estas fórmulas proporcionados por Joaquín Marco (1977, 56-78).
} 


\section{REFERENCIAS}

Alvar, Manuel, 1970. "Romances en pliegos de cordel (siglo XVIII)", en El romancero. Tradicionalidad y pervivencia, Barcelona, Planeta.

Botrel, Jean-François, 1993. Libros, prensa y lectura en la España del siglo XIX, Madrid, Fundación Germán Sánchez Ruipérez.

Camarena, Julio, y Maxime Chevalier, 1995. Catálogo tipológico del cuento folklórico español: cuentos maravillosos, Madrid, Gredos.

CÁtedra, Pedro M., 2002. Invención, difusión y recepción de la literatura popular impresa (siglo XVI), Mérida, Editora Regional de Extremadura.

Caro Baroja, Julio, 1990. Ensayo sobre la literatura de cordel, Madrid, Itsmo.

Cortés Hernández, Santiago, 2003. "Vida de San Albano: herencia del teatro del Siglo de Oro en los pliegos de cordel”, Revista de Literaturas Populares 3-2, 73-91.

Deyermond, Alan, 2005. "La literatura oral en la transición de la Edad Media al Renacimiento", Acta Poetica 26 (1-2), 35-54.

DíAz Roig, Mercedes, (ed.), 2003. El romancero viejo, Madrid, Cátedra.

Frenk, Margit, 1997. Entre la voz y el silencio, Alcalá de Henares, Centro de Estudios Cervantinos.

García de Enterría, María Cruz, 1973. Sociedad y poesía de cordel en el Barroco, Madrid, Taurus.

—, 1983. Literaturas marginadas, Madrid, Playor.

—, 1988. "Romancero: ¿cantado-recitado-leído?”, Edad de Oro 7, 89-104.

MARCO, Joaquín, 1977. Literatura popular en España en los siglos XVIII y XIX (una aproximación a los pliegos de cordel), Madrid, Taurus, tomo I.

Mendoza Díaz-Maroto, Francisco, 1989. Introducción al romancero oral en la provincia de Albacete, Albacete, Instituto de Estudios Albacetenses.

—, 2000. Panorama de la literatura de cordel española, Madrid, Ollero \& Ramos. 
Mendoza Díaz-Maroto, Francisco, 2003. “Observaciones sobre los romances recogidos en La Gomera procedentes de pliegos sueltos", en El romancero de La Gomera y el romancero general a comienzos del tercer milenio, Maximiano Trapero (ed.), Tenerife, Cabildo Insular de La Gomera, pp. 295-314.

Moll, Jaime, 1976. "Un tomo facticio de pliegos sueltos y el origen de las Relaciones de Comedias", Segismundo 23-24, 143167.

Niles, John, D., 1999. Homo Narrans. The Poetics and Anthropology of Oral Literature, Pennsylvania, University Press.

ONG, Walter J., 1996. Oralidad y escritura. Tecnologías de la palabra, trad. Angélica Scherp, México, FCE.

Pedrosa, José Manuel, 2004. El cuento popular en el Siglo de Oro, Madrid, Laberinto.

Rodríguez MoÑIno, Antonio, 1968. Construcción crítica y realidad histórica en la poesía española de los siglos XVI y XVII, Madrid, Castalia.

SALAZAR, Flor, 2003. "El romancero vulgar en La Gomera", en Maximiano Trapero (ed.), El romancero de La Gomera y el romancero general a comienzos del tercer milenio, Tenerife, Cabildo Insular de La Gomera, pp. 219-246.

Thompson, Stith, 1955-1958. Motif-Index of Folk Literature, 6 vols, Bloomington-Copenhague, Indiana University-Rosenkilde \& Bagger.

Vélez de Guevara, Luis, 1988. El diablo cojuelo, Ángel R. Fernández e Ignacio Arellano (eds.), Madrid, Castalia. 